\title{
The gentle sex? Assaults on women by women
}

\author{
P. BURDETT-SMITH \& I. ADAMS
}

Accident and Emergency Department, St James' University Hospital Trust, Beckett Street, Leeds

\section{INTRODUCTION}

Assaults on women have been the subject of many studies. (Gayford, 1979; Steinmetz, 1980; Knopp, 1984; Tanne, 1992). The concept of the 'battered wife' is widely accepted (Gayford, 1979). Organizations exist to offer help, counselling and places of safety to victims. However, recent Chief Constables' reports have highlighted an increase in the number of violent crimes perpetrated by women. Therefore, a study was instigated to assess all female victims of assault that attended the Accident and Emergency Department (A\&E) of St James' Hospital, to ascertain if violence to women, by women, is a significant problem.

\section{METHODS}

The Accident and Emergency Department of St James' University Hospital covers the Eastern side of the city and it's suburbs, and receives approximately 78000 new patients per annum. It's sister department - the General Infirmary, covers the Western side of the city, and receives similar numbers.

The study period ran from 22 October 1991 for 11 weeks, encompassing the Christmas and New Year holidays, until the 2nd of January. In addition to the usual history, i.e. the type of assault, weapon used and whether there was any loss of consciousness, all female victims of assault were asked the sex of their assailant, the number of assailants, whether they knew their attacker, and if they had been assaulted previously. The details of past assaults were not recorded and information on age, address, employment, time and date of attendance was collected from A\&E records the following day. 
The authors were mindful of the need not to distress these patients further, and $\frac{\bar{\Phi}}{9}$ additional questions were therefore kept to a minimum. The data was analysed by 3 means of the chi squared test.

\section{RESULTS}

Over the 72 days of the study period, 124 female victims of assault were seen in the Department. This represents $0.18 \%$ of the 15328 attendances during the same $\vec{\circ}$ period. Twelve records were incomplete because of reluctance on the victims part $\overrightarrow{\vec{\omega}}$ to disclose the information. Of the remaining 112, $27(24 \%)$ were victims of assault ${ }_{\infty}^{\omega}$ by other women, two of which were attacked by both men and women but are $\frac{\Phi}{3}$ included in this group.

\section{Analysis}

The results are summarized in Table 1.

Assaults by men on women

Female victims of male violence largely fall into the category of 'battered wives. Fothergill (1990) reported that 'most women were assaulted at home, had been assaulted before and knew their assailant'. This was confirmed in our study. Over half reported previous assaults and $81 \%$ knew their attacker. Nearly always the

Table 1. Assaults on women: analysis of data

\begin{tabular}{lccl}
\hline & Women & Men & Significance \\
\hline Patient & & & \\
$\quad$ Employed & $52(14)$ & $38(32)$ & n.s. \\
Known to victim & $30(8)$ & $81(69)$ & $\mathrm{P}<0.0001$ \\
Previous & $33(9)$ & $52(44)$ & $P<0.05$ \\
$\quad$ Average age & 26 & 29.6 & \\
Assault & & & \\
One assailant & $63(17)$ & $93(79)$ & $\mathrm{P}<0.0001$ \\
Hit once & $18(5)$ & $40(34)$ & $\mathrm{P}<0.01$ \\
Kicked & $63(17)$ & $29(25)$ & $\mathrm{P}<0.001$ \\
Loss of consciousness & $4(1)$ & $13(11)$ & n.s. \\
Weapon & $15(4)$ & $18(15)$ & n.s. \\
Outcome & & & \\
$\quad$ X-ray & $48(13)$ & $33(29)$ & n.s. \\
Fracture & $26(7)$ & $15(13)$ & n.s. \\
Suture & $7(2)$ & $7(6)$ & n.s. \\
Admitted & $0(0)$ & $7(6)$ & $\mathrm{P}<0.0001$ \\
Out patient appointment & $26(7)$ & $28(2)$ & n.s. \\
\hline
\end{tabular}


assailant was the boyfriend, husband, or 'ex'. They were very much more likely to be attacked by just one man, $(93 \%)$ and to be hit once.

There was a higher incidence of loss of consciousness in this group and victims were much more likely to require admission.

\section{Assaults by women on women}

When women attack women, there seems to be much more violent intent. In this group, over one-third $(37 \%)$ were attacked by more than one assailant compared to just $7 \%$ in the male group. Very few $(30 \%)$ know their attacker before the incident and there is a lower incidence of previous assaults. Over $80 \%$ were hit more than once and $63 \%$ kicked, compared to $60 \%$ and $29 \%$ respectively in the male group. Weapons were used equally by both groups with the stiletto heel on a shoe being common among women assailants. On average the patients in this group were younger and more likely to be employed.

\section{Outcome}

Assessment of the injuries inflicted reflects the different force used by the two sexes. The higher incidence of both $\mathrm{X}$-rays and fractures in the female group is a reflection of the more violent intent and the frequency of multiple blows. Seven per cent of both groups required sutures and a similar number required followup. No victims of female violence were admitted, compared to six $(7 \%)$ of those attacked by men. This suggests that although the number of injuries sustained by victims of female attack is higher, the severity of the injuries is less. This is supported by the higher incidence of loss of consciousness in the male group. The day, date and time of attendance was also recorded; (Figs 1 \& 2).

Violence by women occurred mainly at the weekend, although there was a smaller peak midweek. (The figures apply from 1200 to $1200 \mathrm{~h}$ and thus include early morning and late evening on the same day.) In contrast, violence by men is much more evenly spread during the week with a less noticeable peak at weekends. This may represent delay in attending until the assailant is out of the house, but most victims of assault attend within a few hours of the attack.

Distribution by time is also much more even in the male group. Both groups attend the department mainly between 1200 and $0200 \mathrm{~h}$ (male $30(35 \%)$, female 11

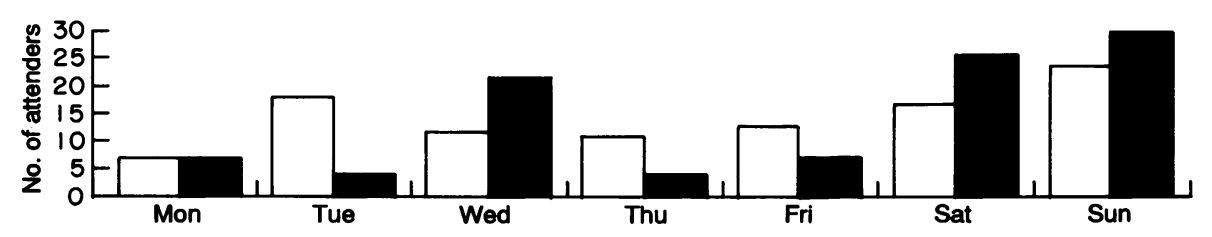

Fig. 1. Attendances by day of the week, $\square$ female, $\square$ male. 


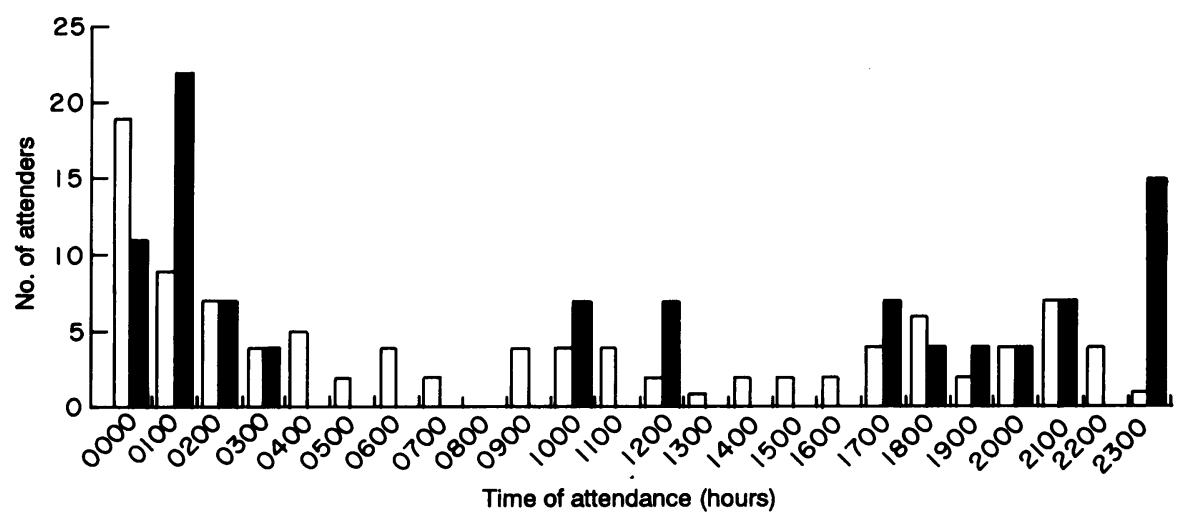

Fig. 2. Hourly rate of attendance, $\square$ male, $\square$ female.

(41\%)). Of the subjects, $61 \%$ attended between 1900 and $0300 \mathrm{~h}$. This is similar to the $63 \%$ reported by Driscoll (1988). There were no attendances by victims of female violence between 0300 and $1000 \mathrm{~h}$ and only four before $1800 \mathrm{~h}$. In contraste victims of male violence presented at any time during the day.

\section{DISCUSSION}

When the problem of assaults on women is addressed, most attention is focuse on assaults by men. A recent North American report (Tanne, 1992) states tha in 1990 'one-third of the women murdered in this country were killed by the husbands, ex-husbands or boyfriends. Each year approximately 626000 violen? victimizations of women are commited by men they know well.' This study confirms that male violence to women is a major problem, but showed that one in fout assaults on women are inflicted by other women. On analysis, there are definite differences between the two groups. Arguments are a common precursor to violences in both groups and although a history of alcohol intake was not obtained speci:fically, most attendances occurred in the early hours of Saturday and Sunda nights. Many of the cases in the female group appear to be the 'jilted' partneis taking revenge, although undoubtedly some are arguments that have escalate into violence.

Comparison with other studies is difficult as these collected data on all assaultsp Different departments workload varies widely; assaults account for between $1.5 \%$ : (Driscoll, 1988) and 3.4\% (Hebedoe et al., 1985) of total attendances. Women compris between $15 \%(8)$ and $28 \%(6)$ of victims in these studies. There are parallels betweent the female group in this study and previous studies of male on male violenct (Driscoll, 1988; Shepherd, 1988; Hocking, 1989). In both there is an increase i⿺ violence at the weekends, alcohol is often involved and the attacks occur in cluks or pubs during the evening and night. It appears that in these cases, women aro acting more like their male peers, and using violence as a means of settling 
differences. By contrast, female victims of male violence attend consistently throughout the week (Hebedoe, 1985) as was confirmed in our study.

No references in the literature to the problem of violent assaults by women on women could be found. Most studies concentrate on male to female violence in the context of 'spouse abuse'. There are reports of the reverse, i.e. 'husband abuse', by violent wives (Steinmetz, 1980), but to our knowledge this is the first report of violence by women on women.

\section{CONCLUSION}

Approximately one quarter of the victims in this study of assaults on women were assaulted by other women. It follows that not all female victims of assault are 'battered wives' and resolving differences by means of violence is not limited to men. This was a preliminary study with small numbers. A larger ongoing study is planned in which questions arising from the study will be addressed.

\section{REFERENCES}

Driscoll P., Smith J., Burdett-Smith P. (1988) A study of assault victims attending three London accident and emergency departments. British Journal of Accident and Emergency Medicine, 3, 5-7.

Fothergill N. J. \& Hashemi K. (1990) A prospective study of assault victims attending a surburban accident and emergency department. Archives of Emergency Medicine 7, 172-177.

Gayford J. J. (1979) The aetiology of repeated serious physical assaults by husbands on wives (wife battery). Medical Science Law 19, 19-24.

Hebedoe J., Charles A., Neilsen J., et al. (1985) Interpersonal violence: patterns in a Danish community. American Journal of Public Health 75(6), 651-653.

Hocking M. A. (1989) Assaults in South East London. Journal of the Royal Society of Medicine 82, 281-284.

Knopp R. K. (1984) Domestic violence: a new priority for emergency medicine. Annals of Emergency Medicine 636, 107.

Shepherd J., Scully C., Shapland M., et al. (1988) Assaults: characteristics of victims attending an inner city hospital Injury 19, 185-190.

Steinmetz S. (1980) Women and Violence: victims and perpetrators. American Journal of Psychotherapy 34(3), 334-350.

Tanne J. H. (1992) Family violence a U.S. health issue. British Medical Journal 304, 203. 